\title{
Influence of Social Factors to the Quality of Life of the Elderly in Malaysia
}

\author{
Abdul Rashid Khan ${ }^{* 1}$ and Ibrahim Tahir ${ }^{2}$ \\ ${ }^{I}$ Penang Medical College, Department of Public Health Medicine, 4 Sepoy Lines, 10450 Georgetown, Penang, Malaysia \\ ${ }^{2}$ Penang Hospital, Residency Road, 10450 Georgetown, Penang, Malaysia
}

\begin{abstract}
Introduction and Aim: The increase in the life expectancy does not necessarily correlate with a higher quality of life. The objective of this study was to determine the influences of social factors to the quality of life of the elderly in Malaysia.

Methodology: This cross sectional study was conducted in Penang, Malaysia among 2005 randomly sampled elderly using the WHOQOL-BREF scale. The sample was randomly collected from a list of residents of the state who are aged 60 years and older who receive the special aid provided by the Penang state government to all elderly residing in Penang irrespective of their socio and economic status.

Results: Regression analysis showed that after controlling for demographic factors which include age, sex, race, marital status, education and employment; living with spouse and family members and being socially active were significantly associated with increased quality of life scores and being dependent on partner and children as compared to being selfdependent on mobility and having poor and moderate support as compared to good social support were significantly associated with decreased quality of life scores.

Conclusion: The quality of life of the elderly is very much influenced by social factors.
\end{abstract}

Keywords: Elderly, Malaysia, quality of life, social support.

\section{INTRODUCTION}

Better health care and nutrition has led to longer life expectancy and with the addition of declining fertility rates has resulted in the increase of the proportion of the elderly population in most countries in the world. It is expected that by 2050 there will be 2 billion elderly in the world with majority of them living in developing countries [1]. The two recent censuses in Malaysia suggest an ageing population trend. The population growth decreased, proportion of the population age 65 years and above increased whereas the proportion of the population below the age of 15 decreased [2]. It is projected that by $2025,13.3 \%$ of Malaysia's population will comprise of elderly [3].

The increase in the life expectancy does not necessarily correlate with a higher quality of life. The concept of Quality of life (QOL) goes beyond morbidity and mortality. An individual's perception of quality of life depends on multidynamic aspects, including the aspects of physical, psychological state, level of independence, social and other relationships [4]. The WHOQOL group defines quality of life as the individuals perception of their position in life with the context of the culture and value systems in which they live in relation to their goals, expectations, standards and concerns [4]. There are many factors which influence the

*Address correspondence to this author at the Penang Medical College, Department of Public Health Medicine, 4 Sepoy Lines, 10450 Georgetown, Penang, Malaysia; Tel: +6042263459; Fax: +6042284285;

E-mail: drrashid10@gmail.com quality of life of older adults and these factors differ compared to other age groups. Besides personal, economic and political factors [5], the elderly also equate quality of life with social contacts, dependency and health [6].

In the elderly, social aspects involve social networks and social support. Better social networks, which is linkages among group of known people, and better social support lead to better health outcome and well-being. Relationships protect from insecurity and psychosocial risk and hence are important for a good quality of life [5, 7]. The lack of meaningful social contacts also leads to withdrawal from social community [8].

Social support is a tangible or an instrumental support which includes physical or financial assistance and emotional support from family, friends and neighbours which leads an individual to feel a sense of belonging [9]. Good social support, both material and emotional support, is an important element in healthy ageing [5, 10-12]. Lack of social support is a risk factor to increased disease susceptibility and mortality and is a predictor for disease outcomes among the elderly $[9,13,14]$ thus leading to lower quality of life.

The assessment for the quality of life are based on the individual's perception regarding physical, emotional and social wellbeing and usually involves subjective evaluation of both positive and negative aspects of life [4] and are important for health evaluation and for intervention. The importance of quality of life among the elderly is for social and health care policy planning and strategies. And social factors especially social support is important for maintaining 
good physical and mental health. Most studies conducted on the quality of life have looked at the general factors which are related to the quality of life including social relations. Few studies have specifically looked at the association of social factors with qualify of life and none in Malaysia until the present study, probably because at present most elderly still live with their families. Reduction in social support correlates with reduced quality of life of the elderly. Due to the inevitable change in the family dynamics in Malaysia, the implication of which is likely to affect the quality of life of the elderly, the policy makers will be caught off guard in the future when this occurs.

The objective of this study was to determine the influences of social factors to the quality of life of the elderly in Malaysia.

\section{METHODOLOGY}

Study design and Setting: This cross sectional study was conducted in Penang, which is one of the most densely populated states in Malaysia and with the highest proportion of elderly population in the country.

Sampling: Participants were taken from the list of recipients of the Penang state government's 'special aid for the elderly' programme. There were 136,292 older adults on this list for the year 2012. Stata was used to calculate the sample size. A sample size of 384 was found to allow the study to have a confidence interval of $\pm 5 \%$. A simple random sample of 400 people was taken from each district (5 districts in Penang state) from the state's 'special aid for the elderly' list to give a total of 2000 elderly participant for the study. All the residents of the state who are aged 60 years and older irrespective of their social and economic status can apply to be placed in the special aid for the elderly list. All those on the list are given RM100 (USD31) per year by the Penang state government.

Tools: The data for this study was acquired using a questionnaire by trained nurses in the participants' house. The nurses were trained comprehensively on the accurate method of data collection using a standard protocol. Besides the baseline demographic information, the quality of life of the respondents was measured using WHOQOL-BREF which has good internal consistency, discriminate validity, criterion validity, concurrent validity, and test-retest reliability [4]. This scale has four domains of multiple items. The physical domain has seven items which include; pain and discomfort, dependence on medication, energy and fatigue, mobility, sleep and rest, activities of daily living and working capacity. The psychological wellbeing domain has six items which include; positive feelings, negative feelings, spirituality, thinking, learning, memory and concentration, body image and self-esteem. The social domain has three items including; personal relationship, sexual activity and social support. And environment domain has eight items including; physical safety and security, physical environment, financial resources, information and skills, recreational and leisure, home environment, access to health and social care and transport. Each item was rated on a five point scale. The raw score for each domain was calculated and then transferred into range between 0-100. Higher scores suggest higher quality of life [15].
Oslo-3 Social Support Scale (OSS-3) was used to measure the social support. OSS-3 consists of three questions. The questions and the scores used were

1. How many people are you so close to that you can count on them if you have a serious personal problem - none (1), 1 to 2 (2), 3 to 5 (3) and $\geq 5$ (4).

2. How much interest and concern do people show in what you do?- a lot (5), some (4), uncertain (3), little (2) and none (1).

3. How easy is it to get practical help from neighbours if you should need it?- very easy (5), easy (4), possible (3), difficult (2) and very difficult (1).

To reflect the social support, the sum score which ranged from 3-14 was categorised into three categories; 3 to 8 'poor support', 9 to 11 'moderate support' and 12 to 14 'strong support' $[16,17]$. Besides the OOS-3 scale, respondents were asked whether they were dependent on anyone for mobility, their living arrangement andparticipation in social activity.

Analysis: Data is tabulated, cross tabulated and analysed statistically using PASW version 18. $t$ test and ANOVA was used to analyse the relationship between the variables. Regression analysis was attempted to determine the significant predictor variables. A probability value of $\mathrm{P}<0.05$ was considered to be statistically significant.

Ethics: The research has received the approval of the Joint Penang independent Ethics Committee (JPEC 110102). All respondents were asked to give a written informed consent before starting the interview. The confidentiality of the respondents is assured.

\section{RESULTS}

A total of 2005 out of the 2250 subjects identified agreed to participate in the study. As shown in Table 1, majority of the participants were women $(68.0 \%)$, in the age groups 60 $69(62.3 \%)$, Malay $(74.0 \%)$, married $(62.4 \%)$, with the highest level of education up to primary school $(63.9 \%)$ and were unemployed at the time of the study (52.4\%). Almost half of the respondents were dependent on themselves for mobility (49.0\%), were living with their children and family $(49.0 \%)$ and majority were actively involved in social organizations $(57.0 \%)$, considered spouse or relatives as the main source of emotional support and had moderate social support (63.6\%) according to the Oslo social support scale.

Table 2 shows the WHOQOL-BREF baseline data. The scores ranged from 22 to 92.5 with a mean value of 59.1. The mean score for the physical, psychological growth, social relations and environment domain was 57.9, 61.7, 56.8 and 59.9 respectively.

As shown in Table $\mathbf{3}$, as the age category increased the mean score decreased $(\mathrm{F}=28.2, \mathrm{p}<0.001)$, Malays $(\mathrm{F}=79.5$, $\mathrm{p}=<0.001)$ and respondents with primary and secondary \& tertiary education $(\mathrm{F}=22.4, \mathrm{p}=<0.001)$ had significantly higher mean scores. The mean scores of men $(\mathrm{t}=3.37$, $\mathrm{p}=0.001)$, those who were employed $(\mathrm{t}=-6.59, \mathrm{p}<0.001)$ and active in social organizations $(\mathrm{t}=-12.0, \mathrm{p}<0.001)$ and the scores of those with strong social support $(\mathrm{F}=64.5, \mathrm{p}<0.001)$ were also significantly higher. 
Table 1. Baseline profile of the participants.

\begin{tabular}{|c|c|c|}
\hline Variables & Frequency & Percentages \\
\hline \multicolumn{3}{|l|}{ Socio Demographic Variable } \\
\hline \multicolumn{3}{|l|}{ Age } \\
\hline $60-69$ & 1250 & 62.3 \\
\hline $70-79$ & 611 & 30.5 \\
\hline$\geq 80$ & 144 & 7.2 \\
\hline \multicolumn{3}{|l|}{ Sex } \\
\hline Men & 642 & 32.0 \\
\hline Women & 1363 & 68.0 \\
\hline \multicolumn{3}{|l|}{ Race } \\
\hline Malay & 1484 & 74.0 \\
\hline Indian & 310 & 15.5 \\
\hline Chinese & 211 & 10.5 \\
\hline \multicolumn{3}{|l|}{ Religion } \\
\hline Islam & 1487 & 74.2 \\
\hline Buddha & 297 & 14.8 \\
\hline Hindu & 203 & 10.1 \\
\hline Others & 18 & 0.9 \\
\hline \multicolumn{3}{|l|}{ Marital Status } \\
\hline Married & 1252 & 62.4 \\
\hline Widow \& Divorce & 573 & 28.6 \\
\hline Single & 180 & 9.0 \\
\hline \multicolumn{3}{|l|}{ Highest Level of Education } \\
\hline Illiterate & 144 & 7.2 \\
\hline Non formal & 387 & 19.3 \\
\hline Primary & 1281 & 63.9 \\
\hline Secondary \& Tertiary & 193 & 9.6 \\
\hline \multicolumn{3}{|l|}{ Employment Status } \\
\hline Employed & 955 & 47.6 \\
\hline Unemployed & 1050 & 52.4 \\
\hline \multicolumn{3}{|l|}{ Social Support Variables } \\
\hline \multicolumn{3}{|l|}{ Mobility } \\
\hline Self & 983 & 49.0 \\
\hline Partner & 256 & 12.8 \\
\hline Children & 729 & 36.4 \\
\hline Others & 37 & 1.8 \\
\hline \multicolumn{3}{|l|}{ Living Arrangement } \\
\hline Spouse/Children/family & 1757 & 87.6 \\
\hline Alone & 200 & 10.0 \\
\hline Others & 48 & 2.4 \\
\hline \multicolumn{3}{|l|}{ Active in Social Organizations } \\
\hline Active & 1142 & 57.0 \\
\hline Not active & 863 & 43.0 \\
\hline \multicolumn{3}{|l|}{ Social Support (According to OSS 3) } \\
\hline Poor support & 326 & 16.3 \\
\hline Moderate support & 1275 & 63.6 \\
\hline Strong support & 404 & 20.1 \\
\hline
\end{tabular}

Table 2. Baseline data on WHOQOL-BREF questionnaire.

\begin{tabular}{|l|c|}
\hline \multicolumn{1}{|c|}{ WHOQOL-BREF } & Score \\
\hline \hline Total WHOQOL-BREF score & \\
Minimum & 22 \\
Maximum & 92.5 \\
Mean (SD ) & $59.1(11.1)$ \\
\hline Physical & \\
Minimum & 6 \\
Maximum & 94 \\
Mean (SD) & $57.9(12.9)$ \\
\hline Psychological Growth & \\
Minimum & 13 \\
Maximum & 94 \\
Mean (SD) & $61.7(13.1)$ \\
\hline Social Relations & \\
Minimum & 6 \\
Maximum & 94 \\
Mean (SD) & $56.8(15.4)$ \\
\hline Environment & \\
Minimum & 25 \\
Maximum & 100 \\
Mean (SD) & $59.9(12.5)$ \\
\hline
\end{tabular}

A linear regression (Table 4) was conducted to determine the significant predictor variables associated with the quality of life, $27.3 \%\left(\mathrm{R}^{2} 0.273\right)$ variability in the WHOQOL-BREF score was explained by the variables in the model. After controlling for demographic factors, living with spouse and family members as compared with living alone $(B=8.05$, $\mathrm{p}=0.01)$ and being socially active $(\mathrm{B}=18.62, \mathrm{p}<0.001)$ were significantly associated with increased quality of life scores. Being dependent on partner $(\mathrm{B}=-29.63, \mathrm{p}<0.001)$ and children $(\mathrm{B}=-42.25, \mathrm{p}<0.001)$ as compared to being selfdependent on mobility and having poor $(B=-28.55, \mathrm{p}<0.01)$ and moderate support $(\mathrm{B}=-30.67, \mathrm{p}<0.001)$ as compared to good social support were significantly associated with decreased quality of life scores.

\section{DISCUSSION}

The finding of this study shows an above average score for the total mean WHOQOL-BREFand the scores for all the four domains suggesting a trend towards a higher quality of life. This finding is similar to another study conducted in an old folk's home in Malaysia [18] and in southern Taiwan [19]. Findings from studies conducted in India [20], Myanmar [6] and in Britain [21] also show generally a higher quality of life among the elderly. This is because quality of life is a subjective evaluation and is based on the elderly's perception regarding wellbeing [4]. Although basic cognitive process associated with learning and memory decline with ageing, the elderly have a relatively high life satisfaction and improved social and emotional functioning 
Table 3. Factors associated with the WHOQOL-BREF score.

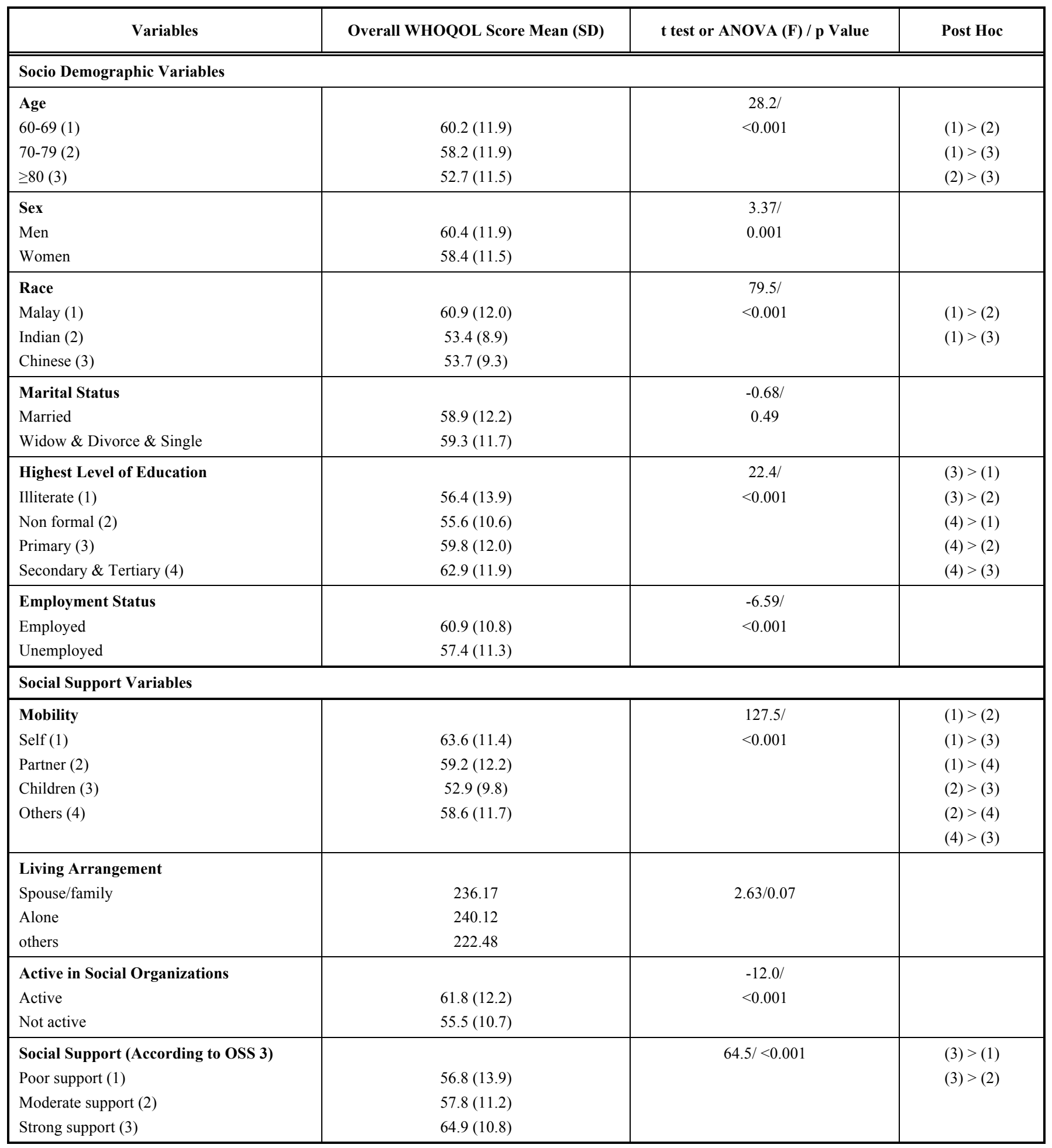

which is termed as paradox of ageing [22]. The elderly have the ability to adapt to changes and have a positive outlook to the changes involved in ageing [23, 24].

The findings of this study show that after controlling for the demographic factors, living with spouse and family members, being self-dependent on mobility, being socially active and having good social support are social factors which are connected with the quality of life.
Social relations protect from insecurity and psychosocial risk and are thus related to well-being and good quality of life [5, 7]. Elderly consider satisfaction with social relationships and participation in community and voluntary work and spending time with family members as positive experiences in ageing [11, 22, 24, 25]. Lack of meaningful social contacts lead to withdrawal from social community [8]. The most common social networks in the elderly are the family relationships which have a positive effect on the 
Table 4. Linear regression.

\begin{tabular}{|c|c|c|c|c|}
\hline & B & $\mathbf{t}$ & $\mathbf{p}$ & $95 \%$ CI \\
\hline $\begin{array}{l}\text { Living Arrangem } \\
\text { Alone (reference) } \\
\text { Spouse/family }\end{array}$ & 8.05 & 2.53 & 0.01 & $1.81 ; 14.28$ \\
\hline $\begin{array}{l}\text { Mobility - } \\
\text { Self (reference) } \\
\text { Partner } \\
\text { Children }\end{array}$ & $\begin{array}{l}-29.63 \\
-42.25\end{array}$ & $\begin{array}{l}-9.72 \\
-20.70\end{array}$ & $\begin{array}{l}<0.001 \\
<0.001\end{array}$ & $\begin{array}{l}-36.60 ;-23.65 \\
-46.25 ;-38.25\end{array}$ \\
\hline Socially Active & 18.62 & 9.79 & $<0.001$ & $14.89 ; 22.35$ \\
\hline $\begin{array}{l}\text { Social Support (A } \\
\text { Strong (reference) } \\
\text { Moderate } \\
\text { Poor }\end{array}$ & $\begin{array}{l}-30.67 \\
-28.56\end{array}$ & $\begin{array}{c}-12.44 \\
-8.93\end{array}$ & $\begin{array}{l}<0.001 \\
<0.001\end{array}$ & $\begin{array}{l}-35.41 ;-25.84 \\
-34.83 ;-22.29\end{array}$ \\
\hline
\end{tabular}

quality of life $[20,26]$. Studies conducted both in the east and west have shown that having good and trusting relationship with family and friends which provide care and trustimproves the quality of life whereas having no good and trusting relationships decrease the quality of life $[8,27,28]$. In the west, where social interaction is common, self-esteem, social approval and help are the benefits of such interactions [29]. Studies show that elderly Thai and Myanmar who have poor relationship, social support and social participation have poor quality of life $[6,30,31]$.

The concept of filial piety is important to Asians [32] and living with extended families rather than living alone, maintaining close contact with and being supported by their extended families is considered as healthy ageing [5, 26, 33]. The psychological, social and physical needs of the elderly are met when they live with family members. Majority of the elderly in Malaysia like their counterpart in Asia live with their children and a study conducted in Malaysia has shown that life satisfaction of the older adults can predict the living arrangement directly or indirectly though social support [25, 34]. Being cognizant of the importance of living with family members and the changes in the family structure in Malaysia, the Malaysian government's objective is to allow the elderly to live in their own homes and in their communities and being cared for by their families, neighbours and communities [35]. However, although older adults prefer living and being taken care by their children [5] but the change in family structure due to urbanization and migration [36] has resulted in changes in societal values. This has resulted in reduced expectations of elderly Asians from their children resulting in many parents not considering children who are unable to care for their parents as non-filial [5]. However this change in family dynamics may cause the elderly to lose opportunities for informal social interactions.

According to Aristotle, man by nature is a social animal and all humans have an innate nature to live in a society and to develop relationships. These social relationships are important for the mental and physical well-being. Social relationships, either bonds with family members, friends and neighbours, provide protection from stress, a sense of belonging and emotional support which can promote active participation in social activities, which is one of the important components of active aging. And participating in social activities also enhances social capital in the elderly. The elderly who do not participate in social activities are at higher risk for health problems [37]. By actively participating in social activities the elderly are able to develop good social networks and integrate into society and prevent social alienation and reduce the risk of morbidity [7, $37,38]$. It was found in a study among the elderly in three cities in Italy, found that the elderly were satisfied with their social life and social integration was an important reason for this [7], because social integration and activities is an important source of life satisfaction and self-esteem [26, 39, 40]. Similar finding was noted in a study in the United Kingdom which found that decline in social activities due to reduced social networks and support was the reason for reduced WHOQOL scores as age increased [39]. Studies among the elderly in Thailand found that social participation was significantly related to successful ageing and was a significant predictor variable [27, 31]. It was found in a study among the elderly in India found that the elderly living in urban areas are more actively involved in social activities and had better social relationship scores than the elderly who lived in villages who had lower scores due to less opportunity for socialization [20]. Not being mobile and dependent on others for mobility can reduce social interaction and result in poor quality of life as shown in a study conducted in Thailand [30]. In a qualitative study among the middle aged and older adults in Hong Kong showed that the respondent considered active participation in different activities and actively engaging in community activities as part of positive ageing [5]. In Malaysia, slightly more than half of the elderly in Malaysia are interested in participating in community activities, more men compared to women and more rural folks compared to urban [41].

Social support is the emotional and practical support received from families and friends [42] and is important for emotional, physical and spiritual well-being of older people [43]. Objective social support i.e. what is actually received or subjective i.e. what is perceived to have been received [44] either in the form of physical, financial and emotional support from social ties and networks especially from family and friends is important [45] for healthy ageing especially among Asians $[5,26]$. Support from family and friends help 
overcome loneliness and health problems related to ageing. The lack of social support can lead to psychological stress and reduced self-esteem [46, 47]. In Asia, family relations are an important aspect of healthy ageing among the elderly [26] and the lack of social support from family and friends may likely cause the individual to perceive old age as uncertain and insecure. A study in Taiwan showed that family support and interaction contributed positively to quality of life [19]. Similarly a study in Myanmar found that family and social relationships were positively related to better WHOQOL scores and that family relationships and good social support were significant predictors for better quality of life [6]. In a study among the elderly retirees in Thailand found that among other factors, social support was a significant predictor for quality of life [31]. Understanding the importance of social support, the Malaysian National Policy and the plan of action for older persons were proposed with the objective to improve the quality of life of older persons with the support of family and community [48]

\section{LIMITATION}

Because this study was conducted in a relatively prosperous state in Malaysia with majority of its population living in urban and semi urban areas, the findings of this study may differ from other states in Malaysia which are less prosperous and have higher proportion of elderly residing in the rural areas.

\section{CONCLUSION}

The objective of this study was to determine the influences of social factors to the quality of life of the elderly in Malaysia. This study has shown that the quality of life of the elderly is very much influenced by social factors especially living arrangements, social participation and social support. As in most Asian population social support was high but this study adds that social support becomes an issue when it falls. In order to meet the challenges of the projected social changes there is an important need to understand the changing social needs of the elderly and to ensure that these changes do not compromise the quality of life of the elderly. It is hence imperative that studies be conducted focussing on the quality of life of elderly and their social needs. Such studies will provide information for policy makers to plan interventional strategies.

\section{CONFLICT OF INTEREST}

The authors confirm that this article content has no conflict of interest.

\section{ACKNOWLEDGEMENTS}

The authors would like to thank Mr Phee Boon Poh and the Penang state government for the grant and support rendered in making this study a success.

This research was funded by the Economic Planning Unit of the Penang State Government, Malaysia.

\section{REFERENCE}

[1] Edwards P. Active agieng: a policy framework. Geneva 2002.

[2] Malaysia DoS. Population and housing census, Malaysia 2010 (2010 Census). Putrajaya: department of statistics Malaysia; 2010 [Cited: 5 January 2012].

[3] Nations U. World population ageing. New York, NY: Department of Economic and Social Affairs, Population Division 2007.

[4] The World Health Organization Quality of Life Assessment (WHOQOL): development and general psychometric properties. Soc Sci Med 1998; 46(12): 1569-85.

[5] Chong AM-L, Ng S-H, Woo J, Kwan AY-H. Positive ageing: the views of middle-aged and older adults in Hong Kong. Ageing and Society 2006; 26(02): 243 .

[6] Naing MM, Nanthamongkolchai S, Munsawaengsub C. Quality of life of the elderly people in einme township irrawaddy division, Myanmar. Asia J Public Health 2010; 1(2): 4-10.

[7] Cavallero P, Morino-Abbele F, Bertocci B. The social relations of the elderly. Arch Gerontol Geriatr 2007; 44(Suppl 0): 97-100.

[8] Holmen K, Furukawa H. Loneliness, health and social network among elderly people--a follow-up study. Arch Gerontol Geriatr 2002; 35(3): 261-74.

[9] Tomaka J, Thompson S, Palacios R. The relation of social isolation, loneliness, and social support to disease outcomes among the elderly. J Aging Health 2006; 18(3): 359-84

[10] Cutrona C, Russell D, Rose J. Social support and adaptation to stress by the elderly. Psychol Aging 1986; 1(1): 47-54.

[11] Depp CA, Jeste DV. Definitions and predictors of successful aging: a comprehensive review of larger quantitative studies. Am J Geriatr Psychiatry 2006; 14(1): 6-20.

[12] Luo L, Kao SF, Hsieh YH. Positive attitudes toward older people and well-being among chinese community older adults. J Appl Gerontol 2009; 29(5): 622-39.

[13] Berkman LF, Glass T, Brissette I, Seeman TE. From social integration to health: Durkheim in the new millennium. Soc Sci Med 2000; 51(6): 843-57.

[14] Zhang X, Norris SL, Gregg EW, Beckles G. Social support and mortality among older persons with diabetes. Diabetes Educ 2007; 33(2): 273-81.

[15] Group TW. WHOQOL-BREF introduction, administration, scoring and generic version of the assessment. Geneva: World Health Organization 1996.

[16] Dalgard OS, Dowrick C, Lehtinen V, et al. Negative life events, social support and gender difference in depression: a multinational community survey with data from the ODIN study. Soc Psychiatry Psychiatr Epidemiol 2006; 41(6): 444-51.

[17] Brevik JI, Dalgard OS. The Health Profile Inventory. Oslo: University of Oslo 1996.

[18] Rashid A, Manan AA. The Quality of life of Elderly Living in a Home for the aged in Penang Malaysia. Middle East J Age Ageing 2013; 10(2): 13-21.

[19] Tseng SZ, Wang RH. Quality of life and related factors among elderly nursing home residents in Southern Taiwan. Public Health Nurs 2001; 18(5): 304-11.

[20] Mudey A, Ambekar S, Goyal RC, Agarekar S, Wagh VV. assessment of quality of life among rural and urban elderly population of Wardha District, Maharashtra, India. Ethno Med 2011; 5(2): 89-93.

[21] Bowling A, Seetai S, Morris R, Ebrahim S. Quality of life among older people with poor functioning. The influence of perceived control over life. Age Ageing 2007; 36(3): 310-5.

[22] Carstensen LL, Lockenhoff CE. Aging, emotion, and evolution: the bigger picture. Ann N Y Acad Sci 2003; 1000: 152-79.

[23] Čeremnych J, Alekna V. The views on ageing of elderly females living in community. Gerontologija 2006; 7(4): 180-7.

[24] Society AP. Attitudes towards ageing: a survey conducted by the Australian Psychology Society. Australia Australian Psychological Society 2007.

[25] Shahar S, Earland J, Abd Rahman S. Social and health profiles of rural elderly Malays. Singapore Med J 2001; 42(5): 208-13.

[26] Hung L-W, Kempen G, Vries NKD. Crosscultural comparison between academic and lay views of healthy ageing: a literature review. Ageing and Society 2010; 30(8): 1373-91.

[27] Nanthamongkolchai S, Tuntichaivanit C, Munsawaengsub C, Charupoonphol P. Successful ageing: a case study of Rayong Province, Thailand. Asia J Public Health 2011; 2(1): 35-9. 
[28] Netuveli G, Wiggins RD, Hildon Z, Montgomery SM, Blane D. Quality of life at older ages: evidence from the English longitudinal study of aging (wave 1). J Epidemiol Commun Health 2006; 60(4): 357-63.

[29] Auld CJ, Case AJ. Social exchange processes in leisure and nonleisure settings: A review and exploratory investigation. J Leisure Res 1997; 29(2): 183-200.

[30] Assantachai P, Maranetra N. Nationwide survey of the health status and quality of life of elderly Thais attending clubs for the elderly. J Med Assoc Thai 2003; 86(10): 938-46.

[31] Nanthamongkolchai S, Pasapun U, Charrupoonphol P, Munsawaengsub C. Quality of life of the early retired government officers in Nonthaburi province. J Public Health 2008; 38(3): 407-15.

[32] Laidlaw K, Wang D, Coelho C, Power M. Attitudes to ageing and expectations for filial piety across Chinese and British cultures: a pilot exploratory evaluation. Aging Mental Health 2010; 14(3): 283-92.

[33] HC H. Exploring elderly people's perspective on successful ageing in Taiwan. Ageing Society 2007; 27(1): 87-102.

[34] Huerta-Quintanilla R, Kooshiar H, Yahaya N, Hamid TA, Abu Samah A, Sedaghat Jou V. Living Arrangement and life satisfaction in older malaysians: the mediating role of social support function. PLoS One 2012; 7(8): e43125.

[35] Sim OF. Ageing in Malaysia: national policy and future direction. Kuala Lumpur: Faculty of Business and Accountancy, University of Malaya 2001.

[36] Ambigga KS, Ramli AS, Suthahar A, Tauhid N, Clearihan L, Browning C. Bridging the gap in ageing: translating policies into practice in Malaysian Primary Care. Asia Pac Fam Med 2011; 10(1): 10-2.

[37] Selvaratnam DP, Bakar NA, Idris NAH. Economic well-being and morbidity of the eldelry in Malaysia. J Modern Account Audit 2010; 6(4): 45-51.
[38] Moorer P, Suurmeijer T. The effects of neighbourhoods on size of social network of the elderly and loneliness: a multilevel approach. Urban Stud 2001; 38(1): 105-18.

[39] Bowling A, Farquhar M, Browne P. Life satisfaction and associations with social network and support variables in three samples of elderly people. Int J Geriat Psychiat 1991; 6(8): 549-66.

[40] Pinquart M, Sörensen S. Influences of socioeconomic status, social network, and competence on subjective well-being in later life: a meta-analysis. Psychol Aging 2000; 15(2): 187-224

[41] Tan PC, Ng ST, Tey NP, Halimah A. Evaluating programme needs of older persons in Malaysia. Kuala Lumpur: Faculty of Economics and Administration, University Putra Malaysia 1999.

[42] A G. the social capital of older people. Aging Society 2009; 29: 531 .

[43] Ajrouch KJ, Blandon AY, Antonucci TC. Social networks among men and women: the effects of age and socioeconomic status. J Gerontol Ser B, Psychol Sci Soc Sci 2005; 60(6): S311-S7.

[44] Kuhirunyaratn P, Pongpanich S, Somrongthong R, Love EJ, Chapman RS. Social support among elderly in Khon Kean province, Thailand. Southeast Asian J Trop Med Public Health 2007; 38(5): 11 .

[45] Minicuci N, Maggi S, Pavan M, Enzi G, Crepaldi G. Prevalence rate and correlates of depressive symptoms in older individuals: the Veneto Study. J Gerontol A Biol Sci Med Sci 2002; 57(3): M15561 .

[46] Bøen H. Characteristics of senior centre users - and the impact of a group programme on social support and late-life depression. Norsk Epidemiologi 2012; 22(2): 261-9.

[47] Cohen S, Wills TA. Stress, social support, and the buffering hypothesis. Psychol Bull 1985; 98(2): 310-57.

[48] Tahir FM. The changing age structures of populations and their implications for development. New York 2007 Available from: http://familyrepository.lppkn.gov.my/144/1/Country_Statement_40 th_session_2007.pdf $\left[10^{\text {th }}\right.$ February 2014]. 